\title{
Hiding Encryption Text by DNA using Exploiting Modification Direction Algorithm
}

\author{
Mohammad S. Hashim \\ mohammad.csp85@student.uomosul.edu.iq \\ Melad J. Saeed \\ Department of Computer Science \\ College of Computer Science and Mathematiics \\ University of Mosul, Mosul, Iraq
}

Received on: 10/01/2021

Accepted on: 01/03/2021

\begin{abstract}
Local networks and the Internet increase day by day, and a large amount of information is transferred across these networks every day resulting in a dramatic increase in the information security threats.

Therefore, it was necessary to use the techniques that ensure the security and the confidentiality of the transferred information. Secret writing is a general term which is used to refer to the protection of information from attackers, and it includes two types of widely used technologies: cryptography and steganography.

The research has presented a security model that fulfils the requirements of confidentiality and safety of the data transferred between the parties of the communication process. This model includes two phases that aim to provide a high level of confidentiality and security for the secret text. New methods have been used to combine cryptography with steganography to attain a high level of secrecy and security where the secret text was encrypted in an innovative and modified way by encoding DNA (Deoxyribo Nucleic Acid) and hiding the resulting encrypted text inside images by means of EMD (Exploiting Modification Direction) method.

This method has been applied on a number of images and texts, and the measurement of PNSR (88.5382, 87.0293, 97.8257), MSE (0.000015, 0.000019, $0.00004), \mathrm{CO}(0)$ and Q-Factor $(0.3521,3458,0.3354)$ values in the resulting hidden images have been yielded good results.
\end{abstract}

Keywords: Networks, Information Security, Cryptography, Steganography, DNA.

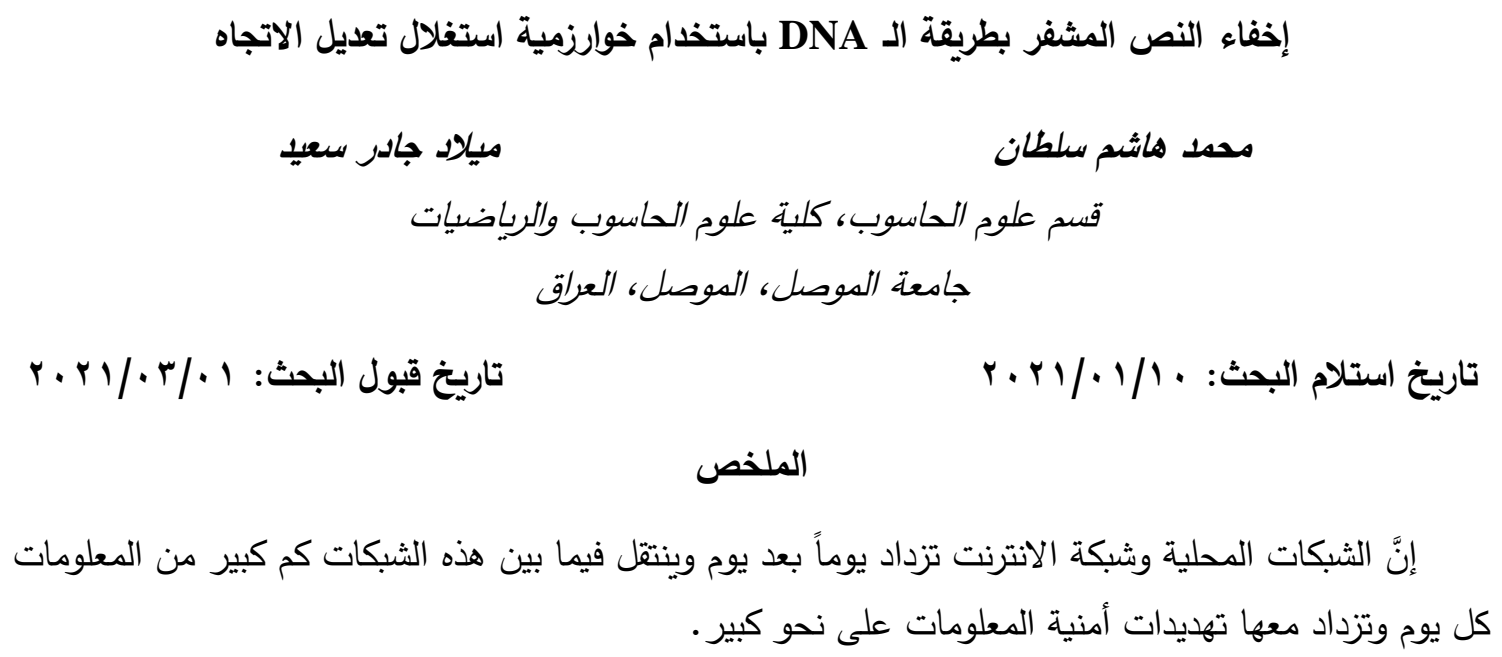


ولذلك كان لا بد من استخدام تقانات تعمل على حفظ أمن المعلومات المنقولة وسريتها؛ فالكتابة السرية هو مصلح

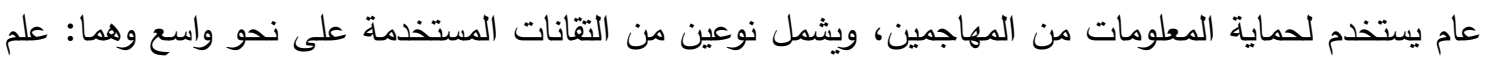
التشفير (Cryptography) وعلم الإخفاء (Steganography).

فقد قدم البحث أنموذجاً أمنياً يحقق متطلبات الإهاء سرية وسلامة البيانات المتنقلة بين أطراف الاتصال؛ إذ يتضمن مرحلتين والتي تهدف إلى توفير مستوى عالٍ من السرية والأمنية للنص السري؛ إذ تم الدمج بين التثفير

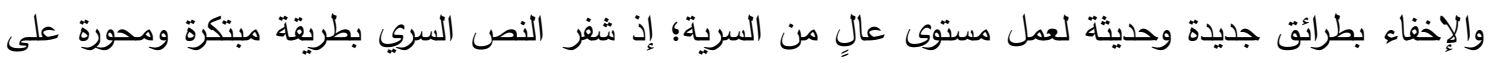
تثفير الـ (الحمض النووي الريبوزي منقوص الاوكسجين) DNA ومن ثم إخفاء النص المشفر الناتج داخل الصور

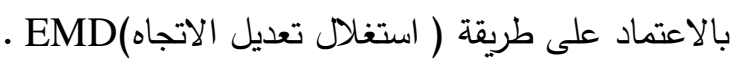

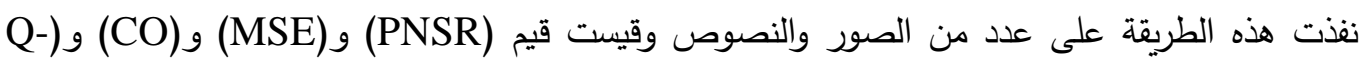

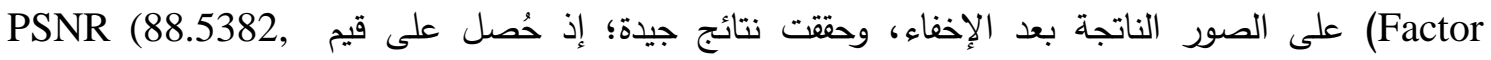
، 87.0293, 97.8257) وقيم (0.3521,0.3458,0.3354) Q-Factor). الكلمات المفتاحية: الثبكات، أمنية المعلومات، علم التثفير، علم الإخفاء، الحمض النووي الريبوزي منقوص الاوكسجين.

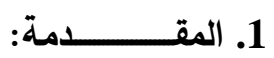

لتوفير الأمنية للبيانات والمعلومات التي تتنقل بين المتصلين مع بعضهم البعض اعتمد على تقنيتين. الأولى هي التثفير "Encryption" والثانية الكتابة المغطاة أو ما تسمى بـ " steganography ". وكثير من المبتدئين

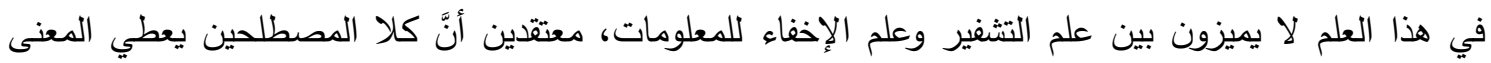

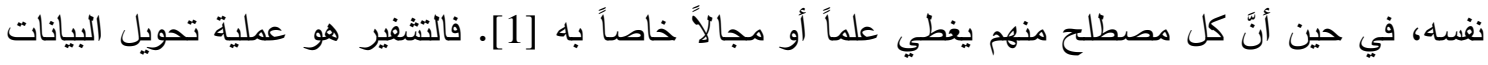

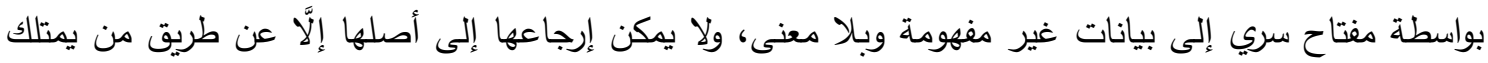

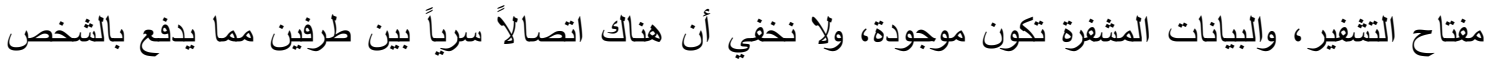

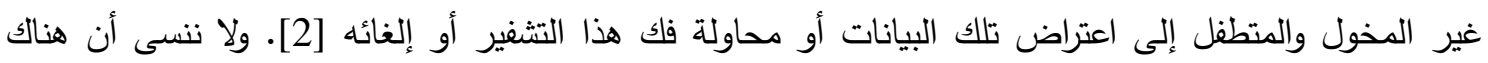

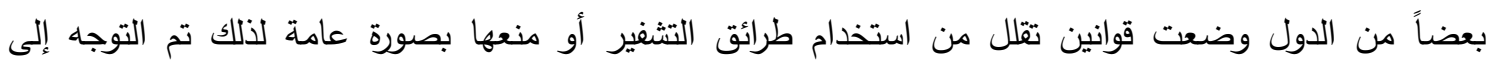
استخدام التقانة الثانية (الكتابة المغطاة) وذلك لإخفاء المعلومات المتبادلة بين الطرفين؛ لأنها تقوم بعملية تضمين

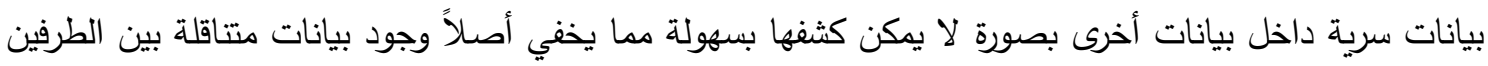

إنَّ التشفير صمم لحماية نوعين من البيانات وهما: أولاً البيانات الثابتة وثانياً البيانات أثثاء النقل، وفي الحالة

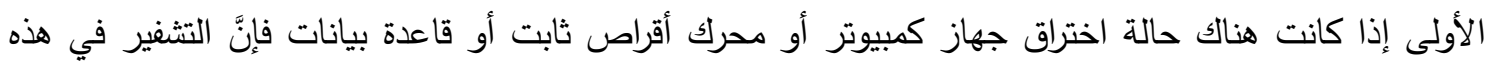

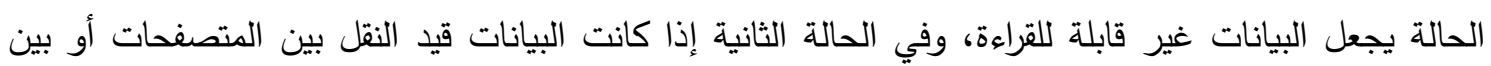
عنواني بريد الكتروني أو عند تحميل البيانات الثخصية إلى السحابة الالكترونية، وحدثت عملية اعتراض لهذهات الهات البيانات من قراصنة البيانات فإن التشفير يحافظ على أمان البيانات المتناقلة خلال هذه المراحل. [5]

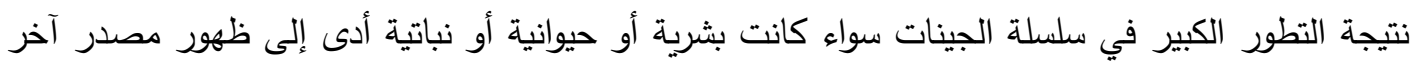
للعشوائية ومناسب لتطبيقات الحوسبة، ويمكن ملاءمته لتتفيذها كخوارزمية للتشفير مع خوارزميات التشفير التقليدية، 
وسميت هذه الخوارزمية بـ (التثفير المعتمد على الـ DNA) [6]؛ إذ تتصف تسلسلات الـ DNA الجينية الطبيعية بعشوائية في تسلسل قواعدها الكيميائية ويطلق عليها بال (نيكليوتيدات) وهي باختصار (الثايمين T) و (الأدنين A

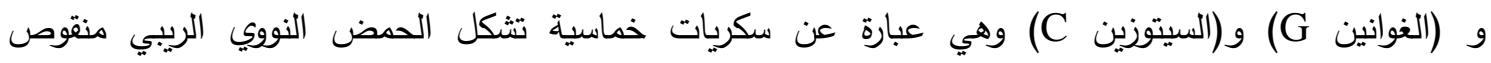
الأوكسجين أو ما يسمى بال (DNA) وكما موضح في الثكل (1) الذي يبين بنية ثلاثية الأبعاد لجزيء DNA

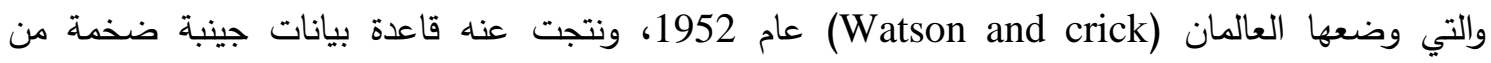

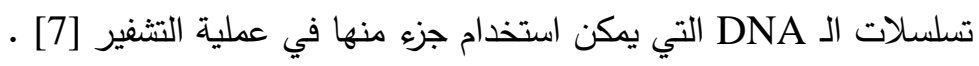

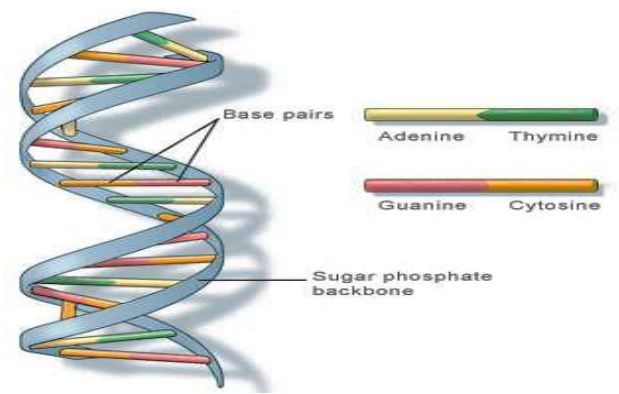

[7] DNA الثكل (1) البنية الفراغية لجزيء

بعد عملية السلسلة لجزيء الـDNA تخزن التسلسلات الناتجة رقمياً بالقراءة الضوئية للتسلسلات الحقيقية ومن ثم تحول إلى الثكل الرقمي وتحفظ في قواعد البيانات الجينية العامة، وتجري عملية تحويل تسلسلات الـ DNA الـDNA من عملية السلسلة، وهي عملية تلي استخلاص الـDNA من خلايا الكائن الحي وقراءة تتالي

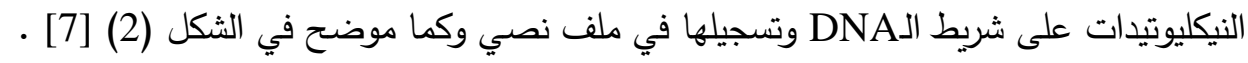

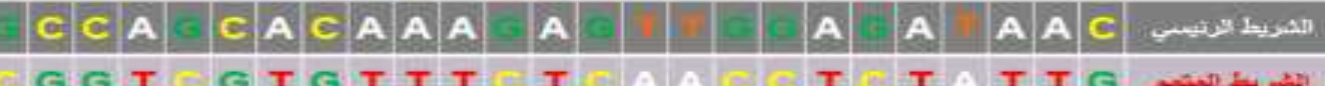

$$
\text { [7] DNA الثكل (2) تسلسلات الـ }
$$

أما بالنسبة إلى الترميز الثنائي لقواعد الـ DNA (النيكليوتيدات) الأربعة وهي (A-T-G-C) فتتم من خلال قواعد التحويل لتسلسلات الـ DNA إلى الصيغة الثنائية كما في الجدول رقم (1) والثكل رقم (3) [8]. الجدول (1) قواعد ترميز حروف الـ DNA ثنائياً [8]

\begin{tabular}{|c|c|c|c|c|c|c|c|c|}
\hline Rule & $\mathbf{1}$ & $\mathbf{2}$ & $\mathbf{3}$ & $\mathbf{4}$ & $\mathbf{5}$ & $\mathbf{6}$ & $\mathbf{7}$ & $\mathbf{8}$ \\
\hline $\mathbf{1 1}$ & $\mathrm{T}$ & $\mathrm{T}$ & $\mathrm{A}$ & $\mathrm{A}$ & $\mathrm{C}$ & $\mathrm{C}$ & $\mathrm{G}$ & $\mathrm{G}$ \\
\hline $\mathbf{1 0}$ & $\mathrm{G}$ & $\mathrm{C}$ & $\mathrm{G}$ & $\mathrm{C}$ & $\mathrm{A}$ & $\mathrm{T}$ & $\mathrm{A}$ & $\mathrm{T}$ \\
\hline $\mathbf{0 1}$ & $\mathrm{C}$ & $\mathrm{G}$ & $\mathrm{C}$ & $\mathrm{G}$ & $\mathrm{T}$ & $\mathrm{A}$ & $\mathrm{T}$ & $\mathrm{A}$ \\
\hline $\mathbf{0 0}$ & $\mathrm{A}$ & $\mathrm{A}$ & $\mathrm{T}$ & $\mathrm{T}$ & $\mathrm{G}$ & $\mathrm{G}$ & $\mathrm{C}$ & $\mathrm{C}$ \\
\hline
\end{tabular}




\begin{tabular}{|c|c|c|c|c|c|c|c|c|c|c|c|c|c|c|c|c|c|c|}
\hline C & A & G & A & T & A & G & A & G & T & C & $\ldots$. & G & A & G & A & T & A & تسلسل \\
\hline 01 & 00 & 10 & 00 & 11 & 00 & 10 & 00 & 10 & 11 & 01 & $\ldots$ & 10 & 00 & 10 & 00 & 11 & 00 & المقابل \\
\hline
\end{tabular}

شكل رقم (3) ترميز تسلسل الـ DNA ثنائياً [8]

أما إذا أردنا تعريف فن الإخفاء بوصفه مصطلحاً حاسوبياً فهو يعني: "علم التضمين" وهو العلم الذي يهتم

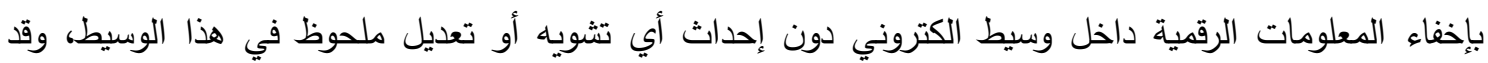

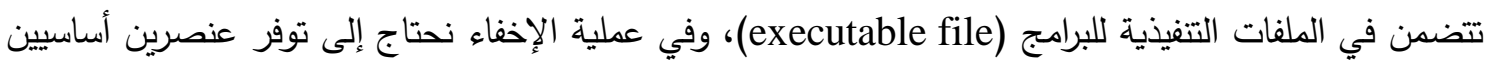

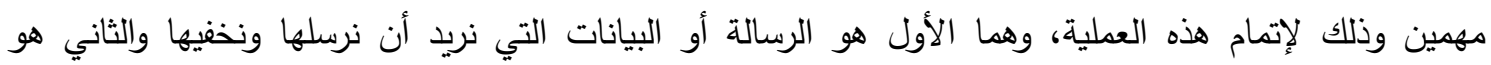
الغطاء (cover) المستخدم لإخفاء هذه البيانات أو الرسالة، تهدف تقانة فن التضمين إلى إخفاء البيانات داخل الخل

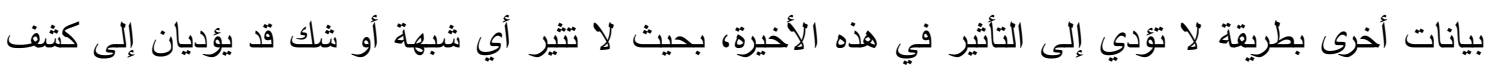

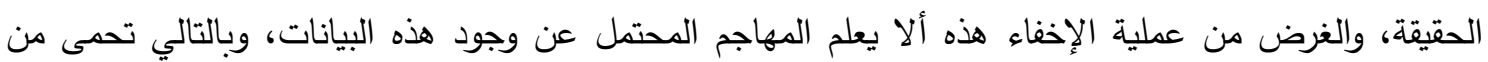

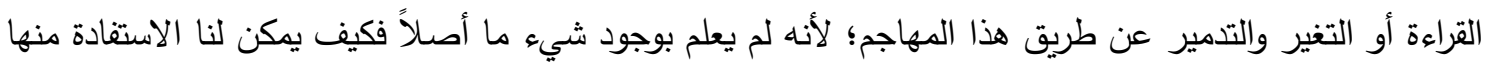
أو تدميرها، وهذا يعني أنّ فَن الاختزال ليس جزاً من فن التشفير، فالفرق بينهما كبير ، وعلى سبيل المثال فإنَّ علم

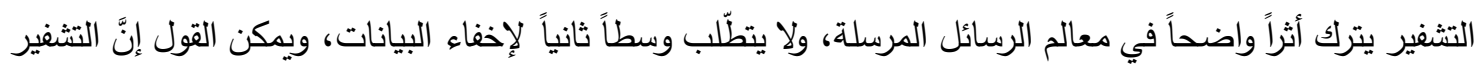

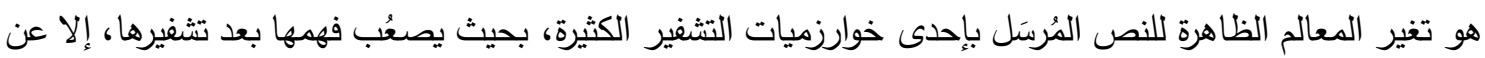

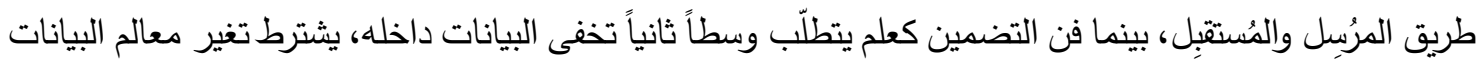

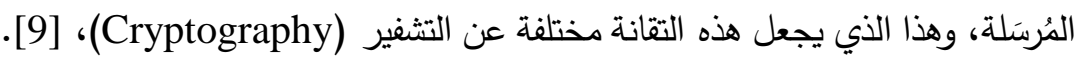

\section{2. الدراسات السابقة:}

من خلال قراءة مجموعة من البحوث والتطرق على الأساليب المستخدمة بها في التشفير والإخفاء فقد لوحظ

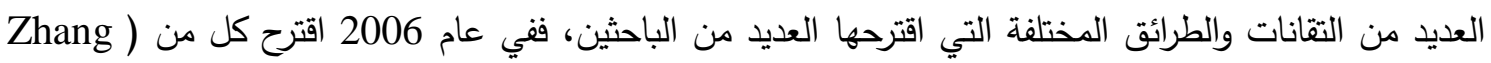

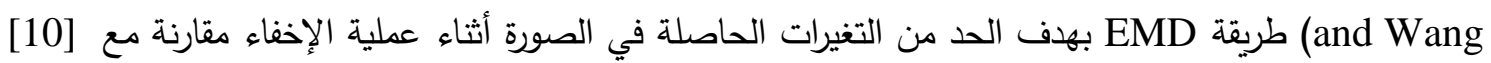

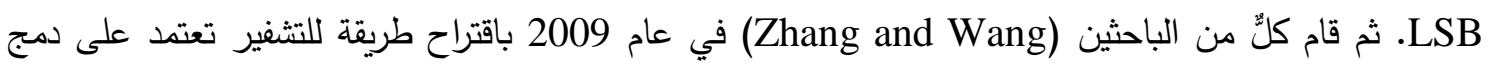

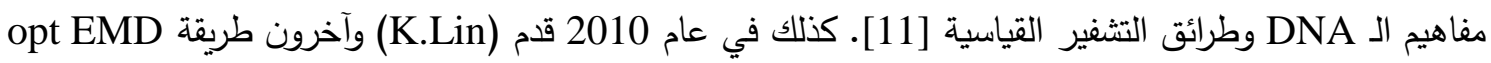
التي تعتمد على تحليل العلاقة بين عدد البكسل n في المجموعة وكمية البيانات التي سوف تخفى داخل الصورة[12]. ثم قدم الباحث (ZHANG Y) وآخرون في عام 2011 طريقة لتشفير البيانات النصية وذلك باستخدام تسلسلات الـ (DNA) ذات أطوال كبيرة، وهذه التسلسلات تستخدم كحامل للبيانات وذلك في عملية فهرسة الـ (DNA) [13]، أما في عام 2013 فقد قدم الباحث (Kuo) وآخرون طريقة جديدة لتطوير خوارزمية الـ

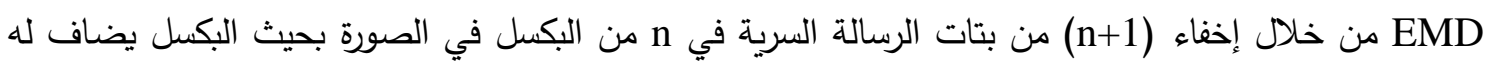

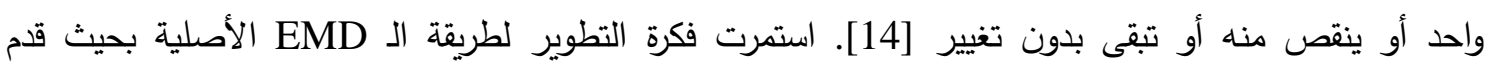
الباحثان (Cheng and Wu) في عام 2014 طريقة لتحسين الـ EMD الأصلية بحيث تقوم هذه الطريقة بطمر رقمين سريين في بكسل واحدة في المجموعة؛ إذ يكون معدل الطمر في البكسل الواحدة في المجموعة مضاعفاً

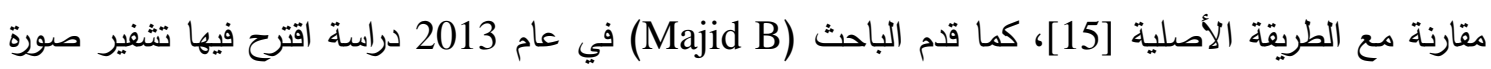

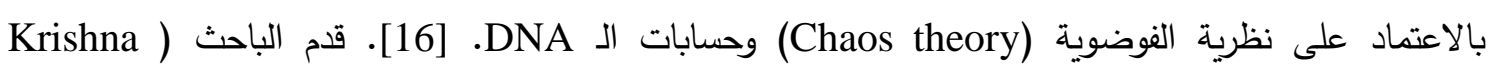

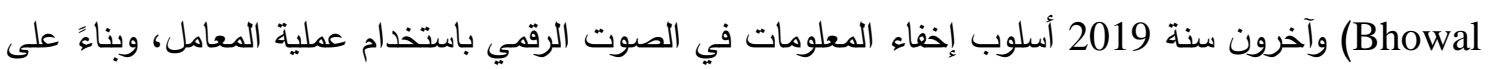


تقانة استغلال تعديل الاتجاه mEMD (Modeifide exploiting Modification Direction) المعدلة [17], وفي 2020 قدما الباحثان Z.Al-kateeb, M.Jader طريقة جديدة لإخفاء النص المشفر بطريقة الـ باستخدام الدالة الفوضوية Chaotic function [18 ] ، ومن ثم قدمت الباحثة Ghada Hamed وآخرون في سنة 2020 بحثاً يقارن فيه بين أنواع إخفاء المعلومات القائمة على الـ (DNA) باستخدام معايير أمنية مهمة مع شرح استراتيجيات إخفاء المعلومات بال (DNA) وذلك للوصول إلى اقتراحات لمساعدة الباحثين على تقديم تقانات تعتمد على الـ (DNA) لتخزين البيانات بثكل آمن وبكفاءة أكثر وموثوقية أعلى [19] ، كما اقترح الباحث وآخرون سنة 2020 خوارزمية موازية ومحسنة وجديدة؛ إذ قام في هذا البحث بتغيير وظيفة خوارزمية الـ

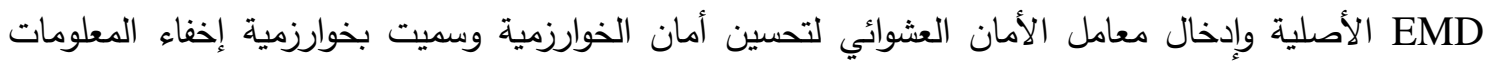

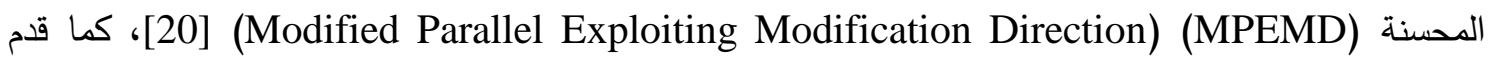
الباحث (Serdar Slolak) في سنة 2020 تقانة جديدة هجينة لإخفاء الصور بالاعتماد على البت الأقل أهمية (Least Significant Bit)(LSB)

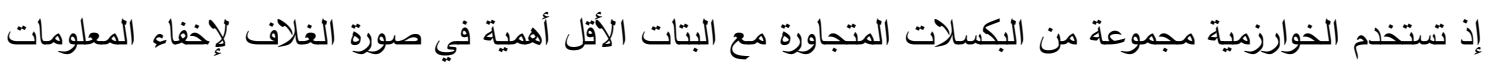
السرية ونتجت الطريقة المقترحة قدرة عالية في التضمين للمعلومات السرية مع الحفاظ على جودة الصورة [21].

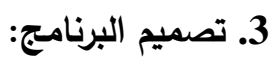

يتضمن البرنامج المقترح العديد من العمليات والمراحل تهدف جميعها إلى توفير مستوى عالٍ من السرية

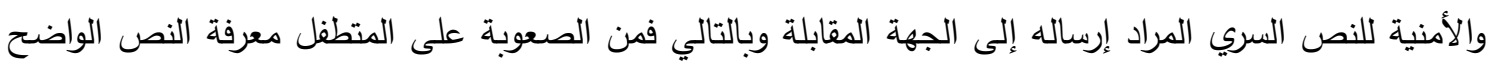
والثكل (4) يوضح المخطط الصندوقي لآلية عمل البرنامج.

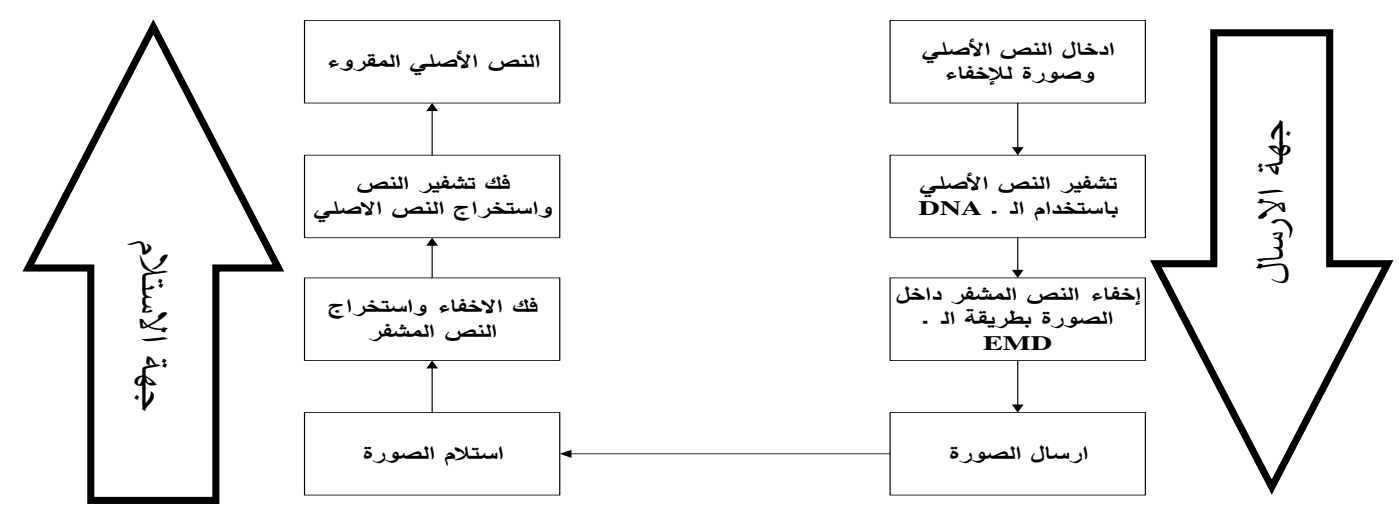

شكل (4) المخطط الصندوقي للبرنامج

4:DNA

$$
\text { الإدخالات: النص الأصلي }
$$

الإخراجات: النص المشفر بال DNA الإدي

1 البداية

2. قراءة النص الأصلي وليكن

3. تحويل حروف الـ SA غلى الاسكي كود وليكن SA 


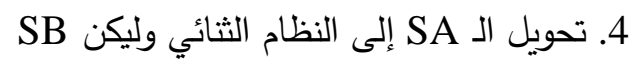

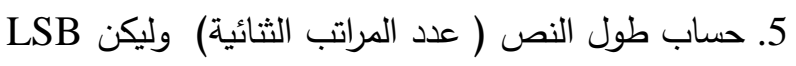

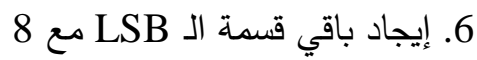

7. ناتج الخطوة السابقة يكون من (0 الى 7) وهو يمثل رقم القاعدة التي سوف تستخدم في التشفير بالاعتماد على

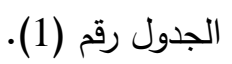

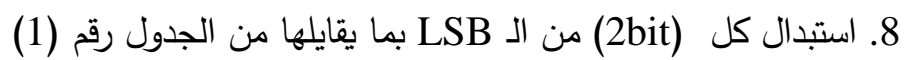

9. هل تم الوصول إلى نهاية النص بالاعتماد على النقطة 5 إذا كانت نعم فينتقل إلى الخطوة رقم 12 إذا كانت

النتيجة لا فنذهب إلى الخطوة رقم 9

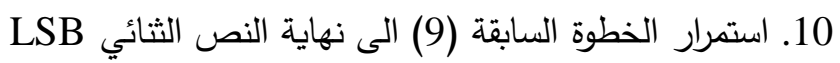

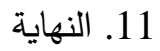

توضح هذه العملية بالمخطط الانسيابي في الثكل (5)

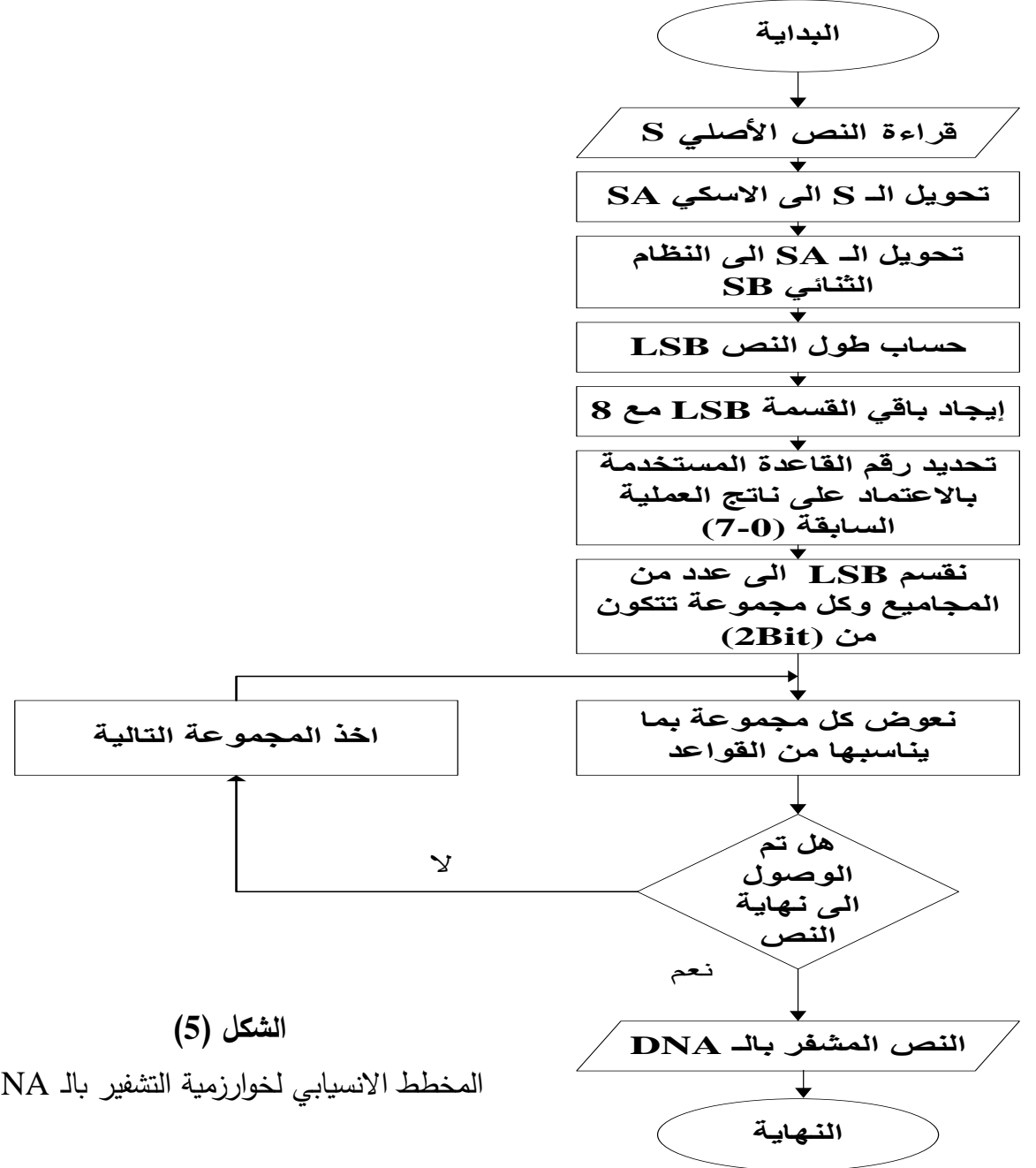

أما بالنسبة لخوارزمية فك الثفرة فتتضمن الخطوات نفسها ولكن بالاتجاه المعاكس.

5. 5وارزمية الإخفاء EMD

الإدخالات: النص المشفر، صورة للإخفاء (cover image) 


$$
\begin{aligned}
& \text { الإخراجات: الصورة بعد الإخفاء }
\end{aligned}
$$

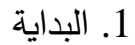

$$
\begin{aligned}
& \text { 2. قراءة النص المشفر وليكن M } \\
& \text { 3L حساب طول النص وخزنه بآخر بايت في الصورة وليكن }
\end{aligned}
$$

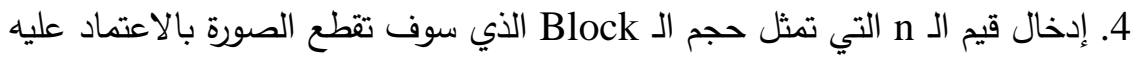

$$
\begin{aligned}
& \text { 5. تحويل النص M إلى النظام الاسكي ومن ثم إلى النظام الثنائي وليكن MB } \\
& \text { 6. قراءة 8bit من النص MB وليكن BMB } \\
& \text { 7. تقسم الـ BMB إلى ثره ثلاثة أجزاء }
\end{aligned}
$$

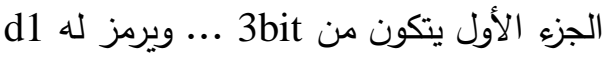

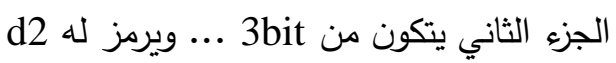

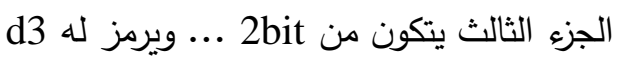

$$
\begin{aligned}
& \text { 8. تقطيع الصورة إلى مجاميع على وفق قيمة الـ } \\
& \text { 9. - حساب قيمة المعادلة الآتية: } \\
& K=(2 n+1) \\
& \text { 10. - 10 تطبيق المعادلة الآتية: } \\
& f=f(g 1, g 2, g 3, \ldots, g n)=\sum_{i=1}^{n}\left(g_{i} * i\right) \bmod k \\
& \text { إذ إنَّ) (g1, g2, g3,....gn تمثل قيم النقاط داخل المجموعة } \\
& \text { n تمثل عدد النقاط داخل المجموعة } \\
& \text { 11. حساب قيمة S حسب المعادلة الآتية: } \\
& \mathrm{S}=\mathrm{d}_{\mathrm{i}}-\mathrm{f} \bmod (2 \mathrm{n}+1)
\end{aligned}
$$

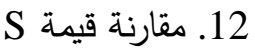

$$
\begin{aligned}
& \text { • إذا كانت قيمة S>=n فإنَّ : } \\
& \mathrm{g}_{\mathrm{s}}=\mathrm{g}_{\mathrm{s}}+1 \\
& \mathrm{~g}_{2 n+1}=\mathrm{g} 2 \mathrm{n}+1-\mathrm{s}-1 \\
& \text { ـ لا ... الرجوع الى الخطوة رقم } 6
\end{aligned}
$$

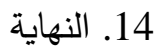




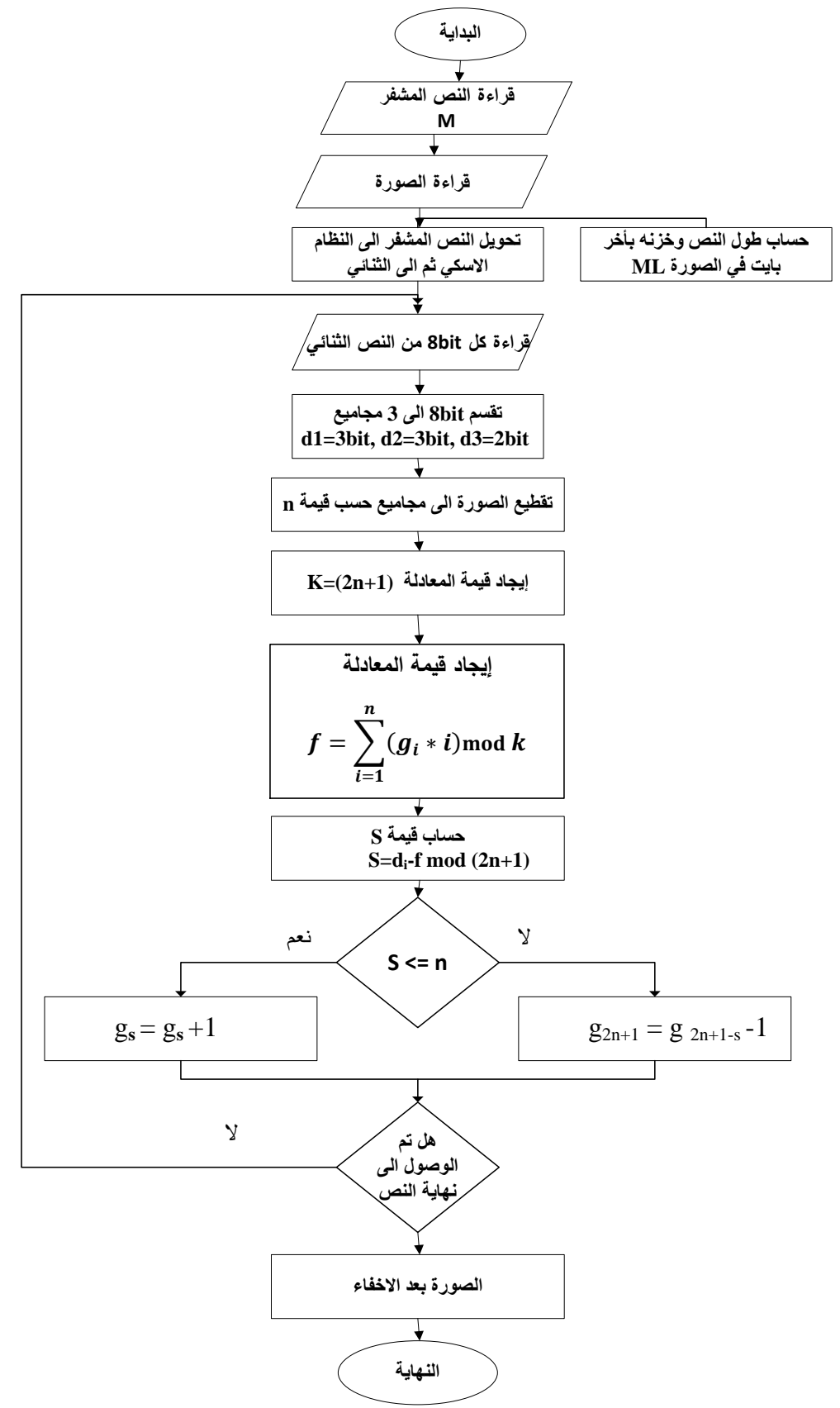

الثكل (6) المخطط الانسيابي لخوارزمية الاخفاء

6. - 5. التطبيق العملي:

فيما يلي التطبيق العملي للبرنامج

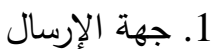




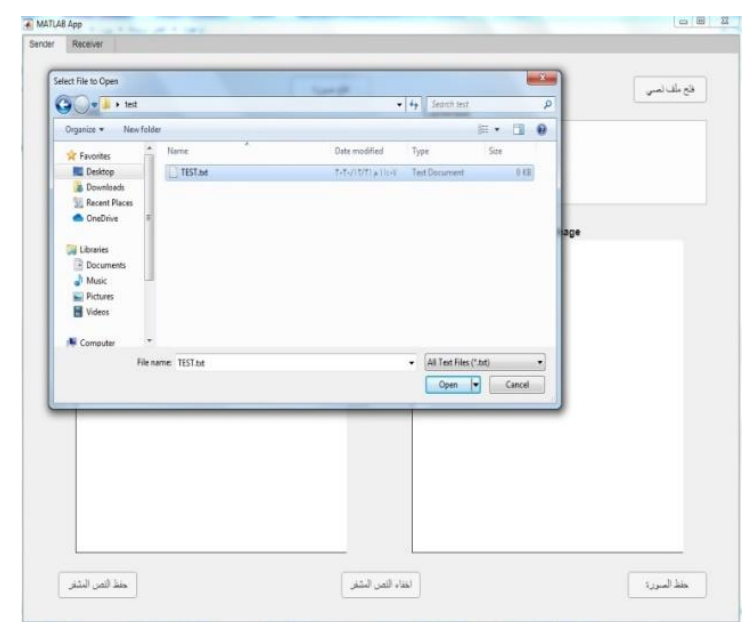

الثكل (8) النص الأصلي والمشفر

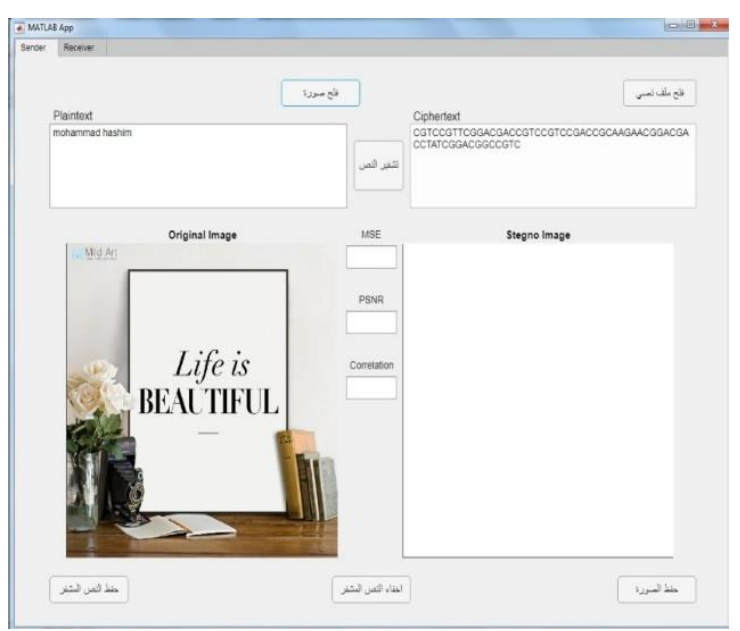

شكل (10) صورة الغطاء
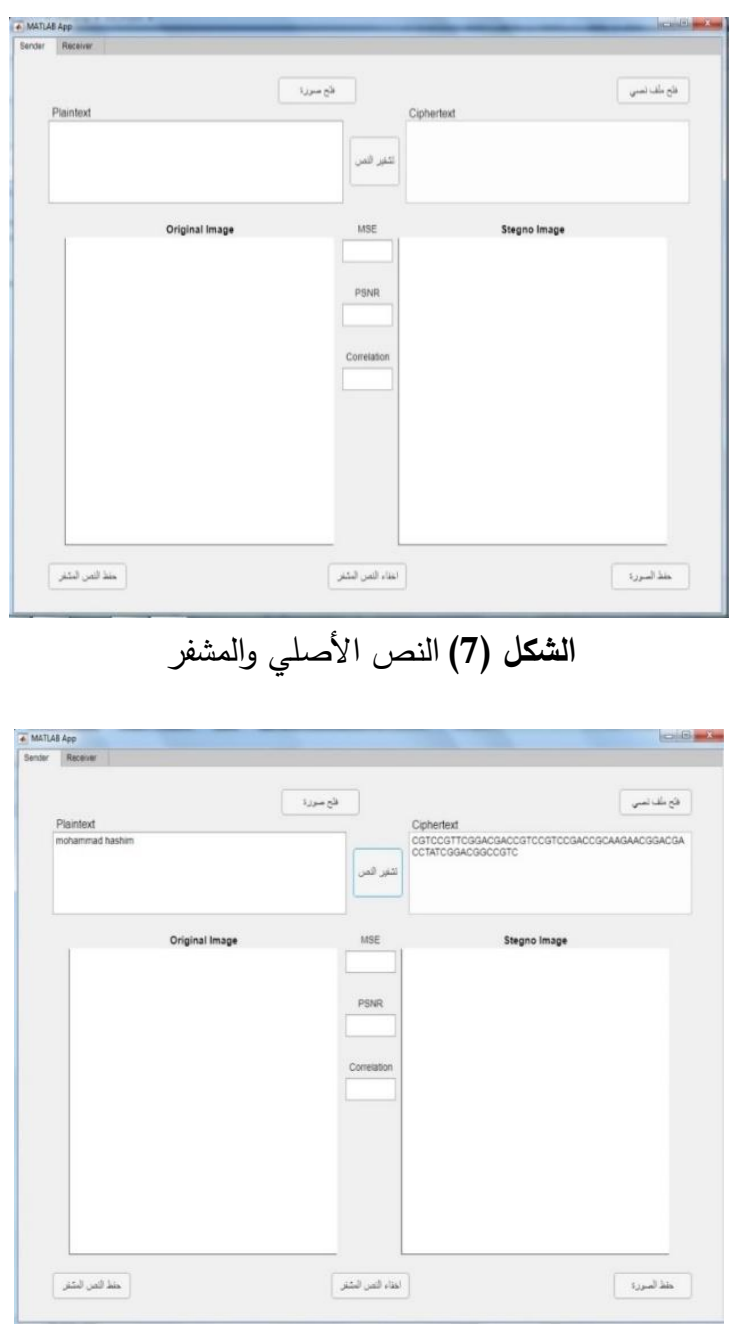

شكل (9) النص الاصلي والمشفر

أما في جهة الاستقبال فتستلم الصورة ومن ثم يستخرج النص المشفر وتفك شفرته كما موضح بالثكل (11) كما حسبت قيم كل من PSNR ,MSE, Co , Q_factor وكانت النتائج جيدة كما موضح بالجدول (2)

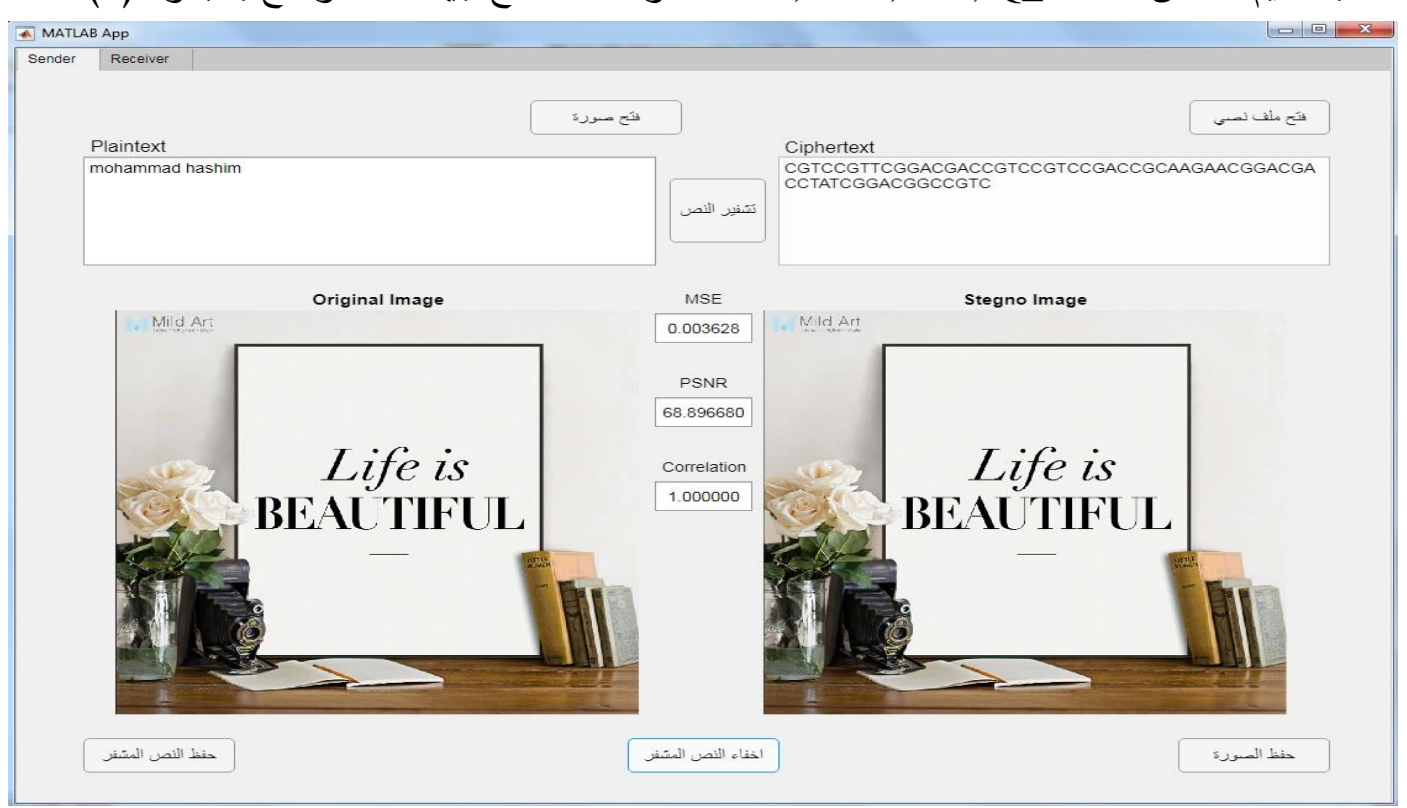

الثكل (11) الصورة بعد الإخفاء 
الجدول (2) جدول النتائج

\begin{tabular}{|c|c|c|c|c|c|c|c|}
\hline $\begin{array}{c}\text { Q- } \\
\text { Factor }\end{array}$ & CO & MSE & PSNR & المشفر & الاصلي & بعد & قبل \\
\hline 0.3521 & 1.0000 & 0.000015 & 88.5382 & \begin{tabular}{|c} 
CATCCGTTC \\
GGACGACCG \\
TCCGTCCGA \\
CCGCAAGAA \\
CAGACGACC \\
GGACTATCG \\
GCCGTC \\
\end{tabular} & 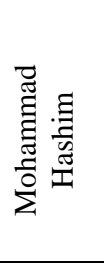 & 6 & \\
\hline 0.3458 & 1.0000 & 0.000019 & 87.0293 & $\begin{array}{c}\text { CATCCGTTC } \\
\text { GGACGACCG } \\
\text { TCCGTCCGA } \\
\text { CCGCAAGAA } \\
\text { CAGACGACC } \\
\text { GGACTATCG } \\
\text { GCCGTC }\end{array}$ & 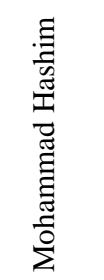 & & \\
\hline 0.3354 & 1.0000 & 0.00004 & 97.8257 & $\begin{array}{c}\text { CATCCGTTC } \\
\text { GGACGACCG } \\
\text { TCCGTCCGA } \\
\text { CCGCAAGAA } \\
\text { CAGACGACC } \\
\text { GGACTATCG } \\
\text { GCCGTC }\end{array}$ & 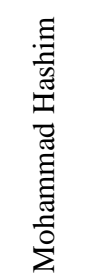 & & \\
\hline
\end{tabular}

7. الاستتتاجات والتوصيات:

• يعطي البرنامج العملي الذي طبق في الرسالة نتائج مقبولة لعدة أنواع مختلفة من الإدخالات مثل النصوص والأرقام والرموز •

• نسبة التشوه والتأثير في الصورة قليلة جداً وذلك ما أثثت في القياسات (PSNR,MSE,CO, Q_factor) على الصورة بعد الإخفاء عند استخدام طريقة الـ EMD في الاخفاء.

• استخدام خوارزمية الـ DNA في التشفير تعدُ كفوءة جداً عند استخدامها مع النصوص القصيرة وخاصةً إذا لإهاء أردنا إخفاءها في صورة؛ وذلك بسبب أنَّ كلَّ حرف من النص الأصلي يتمثل بأربعة أحرف في النص المشفر

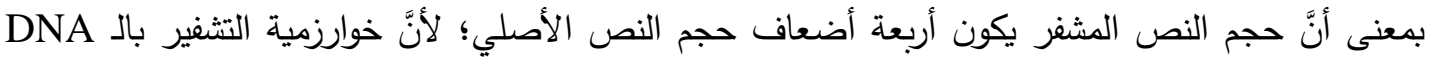
تعتمد على أربعة قواعد لتطبيقها، وهذا بالطبع سوف يأخذ نقاط كثيرة في الصورة ولهذا يفضل استخدام نصوص صغيرة الحجم. • لوحظ أثناء تجربة وفحص البرنامج أنه كلما كانت الصورة ذات ألوان كثيرة ومثبعة أصبح التضمين والإخفاء أكثر كفاءة.

من خلال تطبيق الرسالة والحصول على النتائج السابقة يمكننا تقديم بعض المقترحات المستقبلية لتطوير العمل كاستخدام تقانات العشوائية chaotic في عدد من مراحل البحث لزيادة السرية وجعل النظام أكثر أماناً، وكذلك لكانك إمكانية دمج النظام مع الثبكات العصبية والمنطق المطبب للاستفادة من خصائصهما، وإضافة طرائق تثفير فئن أخرى لجعل النص يمر بأكثر من مستوى من التشفير، وهذا يزيد من سرية النص ويجعله أكثر أماناً. كما أنه

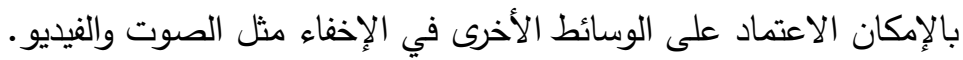




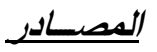

[1] N. Provos and P. Honeyman, (2003), "Hide and Seek: An Introduction to Steganography", IEEE Security and Privacy Magazine, 1(3), 32- 44..

[2] S. Joshi and S. Nipanikar, "Implementation Of Exploiting Modification Direction (Emd) - A Steganography Technique Using Raspberry Pi", International Journal Of Current Engineering And Scientific Research (IJCESR),2(8),(2015).

[3] W. Kuo, J. Cheng and C. Wang, "Data Hiding Method With High Embedding Capacity Character", International Journal of Image Processing (IJIP), 3(6), (2010).

$$
\text { كريم وعباس ، "2019"، تشفير المعلومات لضمان، علاء حمين ومائ، (2008)، "إخفاء المعلومات"، إثراء للنشر والتوزيع. }
$$

[6] G. A, L. T and R. J, 2000, "Dna-based cryptography.,," DIMACS Series in Discrete Mathematics and Theoriti- cal Computer Science, p. 233-249, 54.

[7] A. Aich, A. Sen, S. R. Dash and S. Dehuri, 2015, "A Symmetric Key Cryptosystem Using DNA Sequence with OTP Key," Springer India, pp. 207 216.

د.كندة سليمان ابوقاسم وتيسير عزت سليمان،2019، تثفير النصوص باستخدام OTP من تسلسلات

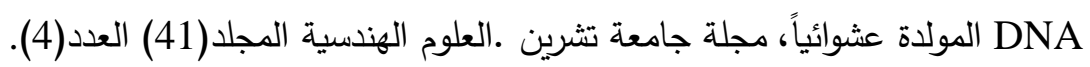

[9] RajKumar, Yadav, et al, (2011), "Anew Image Steganography Approach For Information Security Using Gray Level Images In Spatial Domain", International Journal On Computer Science And Engineering (IJCSE), July.

[10] X. Zhang and S. Wang, 2006, "Efficient Steganographic Embedding by Exploiting Modification Direction", IEEE Communications Letters, 10(11),781783.

[11] Zhang and Wang,2009,"DNA computing-based cryptography ", IEEE 978-14244-3867-9/09.

[12] K. Lin, w. Hong, J. Chen, T. Chen and w. Chiang, 2010, " Data Hiding by Exploiting Modification Direction Technique Using Optimal Pixel Grouping ", 2nd international Conference on Education Technology and Computer (ICETC).

[13] Y. ZHANG, Y. ZHU, Z. WANG and S. RICHARD, 2011, "Index-Based Symmetric DNA Encryption Algorithm," in 4th International Congress on Image and Signal Processing IEEE.

[14] W. Kuo and C. Wang, 2013," Data hiding based on generalized exploiting modification direction method", The Imaging Science Journal,61.

[15] Majid B,2013,"A novel text and image encryption method based on chaos theory and DNA computing", Springer Science Business Media B.V.

[16] C. Chang and H. Wu, 2014, "A Large Payload Information Hiding Scheme Using Two Level Exploiting Modification Direction", Tenth International 
Conference On Intelligent Information Hiding And Multimedia Signal Processing IEEE.

[17] Debasree Chanda, Susanta Biswas, and Partha Sarkar,2019, An Efficient SteganographicApproach to HideInformation in Digital Audio using Modulus Operation The International Arab Journal of Information Technology, Vol. 16, No. 4.

[18] Z. Al-kateeb, M. Jader, 2020, " Encryption and hiding text using DNA coding and hyperchaotic system ", Indonesian Journal of Electrical Engineering and Computer Science, Vol. 19, No. 2, August 2020, pp. 766 774.

[19] Ghada Hamed, Mohammed Marey, Safaa Amin El-Sayed and Mohamed Fahmy Tolba,2020," Comparative Study for Various DNA Based Steganography Techniques with the Essential Conclusions about the Future Research", Faculty of Computer and Information Sciences, Ain Shams University,Cairo, Egypt.

[20] Qi Ke, Qinan Liao and Ruidong Pan,2020," An Improved EMD Parallel Steganography Algorithm", ICCSCT 2020 Journal of Physics: Conference Series 1621.

[21] SERDAR SOLAK,2020," High Embedding Capacity Data Hiding Technique Based on EMSD and LSB Substitution Algorithms", Digital Object Identifier 10.1109/ACCESS.2020.3023197 IEEE Access. 